Psychological Medicine, 1980, 10, 403-406

Printed in Great Britain

\title{
EDITORIAL
}

\section{Language and schizophrenia ${ }^{1}$}

Disturbances of speech are one of the most obvious signs, in an acute episode, of schizophrenia. Most psychopathologists have regarded these disturbances as an indication of an underlying disorder of thought. It was hoped, therefore, that the study of schizophrenic language would not only provide a measure of its deviance but would also throw some light on the construct 'schizophrenia' itself. Unfortunately, the progress of research has been very slow due, in part, to the fact that clinically relevant data, such as other symptoms, have not been taken into account in the design of experiments. There have been several general reviews of the literature (Pavy, 1968; Maher, 1972), so the present essay will deal chiefly with very recent work.

Is the schizophrenic speaker/listener, for the most part, an adequate user of language? A few years ago the answer was that schizophrenics differ markedly from normals in their ability to utilize the syntactic and semantic constraints of language (Maher, 1972). This view has often arisen from a lack of comparison with normal speech production. For instance, Chaika (1974) based her theory of schizophrenic language on the speech errors made by schizophrenics. These speech errors are, however, not unique to schizophrenics; not only are they produced by normal speakers (Fromkin, 1975), but they are also produced by the previous personnel of the White House (Gold, 1974).

The first study to suggest that schizophrenic listeners are aware of syntactic and semantic constraints was carried out by Gerver (1967). He showed that both schizophrenics and normals were better at recalling semantically and syntactically correct sentences than random strings of words. The increase was at least as large in his chronic schizophrenic sample as it was for the normals. Recent studies have replicated this result and extended it further, using other paradigms (Truscott, 1970; Rochester et al. 1973; Carpenter, 1976).

If the formal rules of language are used properly, why are conversations with acute schizophrenics so difficult to follow? One suggestion has been that schizophrenic speech does not contain enough redundancy. This hypothesis has led to much fruitless research using the cloze procedure, a technique based on guessing deleted words from the transcripts of speech. Some researchers have shown that schizophrenic speech is less redundant than normal, i.e. it is more difficult to guess the missing words (Salzinger et al. 1964; Silverman, 1972). Others, however, have not shown this difference (Rutter et al. 1975, 1977, 1978). There are many possible reasons for this discrepancy, the most likely being differences in the way patient samples are drawn. Recently, Manschrek et al. (1979) have shown that the speech of 'thought disordered' schizophrenics was significantly less predictable than 'non-thought disordered' schizophrenics. A non-significant difference between schizophrenic and normal samples when using the cloze technique may simply mean that there were few thought disordered patients in the schizophrenic sample. A tentative conclusion from all this research is that a lack of redundancy is not a defining feature of schizophrenic language in general, but that it may be characteristic of the speech of those schizophrenic patients who have marked thought disorder.

Other variables which might characterize schizophrenic speech, such as loose associations and disruptive clauses, have also been investigated (e.g. Siegel et al. 1976; Rochester et al. 1977), but these variables too cannot be considered as defining features of schizophrenic speech. Rochester and her colleagues (1977) showed that, even in the most severely thought-disordered group, the speech of $80 \%$ of the patients contained very few clauses that could be defined as disruptive.

If the deviancy of schizophrenic language does not lie in an inability to link words together, it must lie elsewhere. One possibility is that the speaker is violating the rules of communication

\footnotetext{
${ }^{1}$ Address for correspondence: Dr Til Wykes, MRC Social Psychiatry Unit, Institute of Psychiatry, De Crespigny Park, Denmark Hill, London SE5 8AF.
} 
(Grice, 1975), rather than strict linguistic rules. This suggestion has provided some interesting results. Researchers have tackled the problem in two different ways. In the first, more experimental, approach one person is required to give another sufficient information to be able to select a coloured disc in an array. When the colours in the array are very similar, more information is needed to make the correct choice. The results of these studies indicate that schizophrenics are indistinguishable from normals when they act as listeners but that they are not very good as communicators (Kantorowitz \& Cohen, 1977; Cohen et al. 1974; Davis \& Blaney, 1976). There was little difference between the groups when the array contained very dissimilar colours; but when the similarity increased, the performance of the schizophrenics as communicators became steadily worse compared with normals.

The second approach to investigating the competence of schizophrenics as communicators uses free speech. In order for a listener to understand what a pronoun refers to, the speaker must refer only to referents in the immediate context (situation reference), in the verbal context (explicit reference), or referents that are so well known to the listener that they can be assumed. The results of these analyses showed that these cohesive links between sentences are often missing (Rochester, 1976; Rochester et al. 1977). The listener's task is made extremely difficult by the failure to provide these links. He must often search for information (e.g. the referent of a noun phrase) that does not exist. This conclusion may well explain the results of Rutter (1979), who found that it was more difficult to reconstruct schizophrenic speech than it was to reconstruct normal speech. If it is not clear how noun phrases are referred to, it is unlikely that more than two or three sentences could be strung together appropriately.

These errors in communication can also be produced by normal adults and children (Maratsos, 1976; Cheadle \& Morgan, 1972), though at a lower frequency than in schizophrenia. There is no information at present on the situations in which more or fewer errors are produced.

Many of the studies of language and schizophrenia have serious methodological flaws (for a full exposition see Blaney, 1978; Schwartz, 1978). There are virtually no studies that quote drug levels or possible socio-economic differences between groups. Also there is often a flagrant disregard for the rules of statistical inference - a problem which is not confined just to language research in psychiatry (White, 1979). Even though standard procedures do exist for specifying the criteria for diagnosis (e.g. Wing et al. 1974; Feighner et al. 1972), very few studies use them. This problem is particularly serious when comparing American and British studies. Few experiments divide the subject population into the various subgroups of schizophrenia or even into acute and chronic. Even fewer make comparisons with patients suffering from mania, severe depression or organic disorders such as dementia, although clinicians have described very different types of 'thought disorder' in each of them.

Some of the differences between different subgroups of schizophrenia may cancel each other out, making it appear that there is no difference between the patient group and the controls. Several studies have cited differences between acute and chronic patients, but few systematic comparisons have been made (Cohen et al. 1974; Kantorowitz \& Cohen, 1977; De Silva \& Hemsley, 1977; Chapman et al. 1977; Blaney, 1974), and no studies have examined factors such as institutionalism, long-term medication, or the course of schizophrenia. One other possible explanation is that the difference between acute and chronic patients has always been present in those patients who will eventually become chronic. In this case, a linguistic index might provide some measure of vulnerability. The only way to investigate this and many other interesting problems would be to carry out longitudinal studies.

Most research has been based on transcripts of schizophrenic speech, but it is by no means clear whether different studies employ the same sorts of rules in the transcription process. Much is lost in transferring the spoken to the written word; the very meaning of a sentence can be distorted if the intonation is not recorded. Consider, for instance, the double meaning of 'John hit the man with the stick'. Future studies should concentrate more on intonational aspects of meaning.

In reviewing the research in this area I have not mentioned any theories that purport to explain the results (Salzinger, 1973; Chapman \& Chapman, 1973; Cromwell \& Dockeki, 1968; Cohen \& 
Camhi, 1967; Frith, 1979). One of the reasons for ignoring cognitive explanations is the paucity of well-controlled tests of hypotheses derived from them. Most theories are not even sufficiently specific to be testable and none is exclusive of any of the others. Frith's theory, that an 'inhibitory process' normally prevents too much information from reaching consciousness but that this process is suppressed in schizophrenics, potentially encompasses all the others. In the Chapmans' theory this process prevents normals from succumbing to their response biases; in Cohen's, it is the function which edits out inappropriate responses.

Research on language has not merely been confined to studies of schizophrenic patients: their relatives have also been investigated. Singer \& Wynne (1966) suggested that the parents of schizophrenics produced more deviant communications than the parents of neurotic patients. Hirsch \& Leff (1975) found only weak confirmation of this result and suggested that it was explained by the production of more speech. While noting that Singer \& Wynne's measures of deviance are by no means perfect, this suggestion does not explain their results. It merely begs the question 'why do the parents of schizophrenics produce more speech?' Further rigorous tests, using other deviance measures, such as those provided by Cohen's and Rochester's work, might provide useful information on genetic factors.

In summary, we have a picture of the schizophrenic who resembles normals in many ways. His errors in referring listeners to relevant information are similar to the errors that are sometimes made in normal conversations. Not all of his language is deviant; in fact, we might go further and say that very little of his language is deviant. But these few differences really are significant. If language research is to have any clinical utility, it must concentrate on investigating these few deviant psycholinguistic variables and relate them to other clinical variables.

TIL WYKES

\section{REFERENCES}

Blaney, P. H. (1974). Two studies on the language behaviour of schizophrenics. Journal of Abnormal Psychology 83, 23-31.

Blaney, P. H. (1978). Schizophrenic thought disorder: why the lack of answers? In Language and Cognition in Schizophrenia (ed. S. Schwartz), pp. 101-116. Lawrence Erlbaum: New Jersey.

Carpenter, M. D. (1976). Sensitivity to syntactic structure, good vs. poor pre-morbid schizophrenics. Journal of Abnormal Psychology 85, 41-50.

Chaika, E. (1974). A linguist looks at 'schizophrenic language'. Brain and Language 1, 257-276.

Chapman, L. J. \& Chapman, J. P. (1973). Disordered Thought in Schizophrenia. Appleton-Century-Crofts: New York.

Chapman, L. J., Chapman, J. P. \& Miller, G. A. (1977). A theory of verbal behaviour in schizophrenia: postscript. In Contributions to the Psychopathology of Schizophrenia (ed. B. A. Maher), pp. 164-167. Academic Press: New York.

Cheadle, J. \& Morgan, R. (1972). Does the chronic psychiatric patient understand plain English? British Journal of Psychiatry 120, 553-560.

Cohen, B. D. \& Camhi, J. (1967). Schizophrenic performance on a word communication task. Journal of Abnormal Psychology 72, 240-246.

Cohen, B. D., Nachmani, G. \& Rosenberg, S. (1974). Referent communication disturbances in acute schizophrenia. Journal of Abnormal Psychology 83, 1-13.

Cromwell, R. L. \& Dockeki, P. R. (1968). Schizophrenic language: a disattention interpretation. In Development in Applied Psycholinguistic Research (ed. S. Rosenberg and J. A. Koplin), pp. 209-260. Macmillan: New York.

Davis, K. M. \& Blaney, P. H. (1976). Overinclusion and self-editing in schizophrenia. Journal of Abnormal Psycho$\log y 85,51-60$.
De Silva, W. P. \& Hemsley, D. R. (1977). The influence of context on language perception in schizophrenia. British Journal of Social and Clinical Psychology 16, 337-345.

Feighner, J. P., Robins, E., Guze, S. B., Woodruff, R. A., Winokur, G. \& Muñoz, R. (1972). Diagnostic criteria for use in psychiatric research. Archives of General Psychiatry 26, 57-63.

Frith, C. D. (1979). Consciousness, information processing and schizophrenia. British Journal of Psychiatry 134, 225235.

Fromkin, V. A. (1975). A linguist looks at 'a linguist looks at "schizophrenic language" ". Brain and Language 2, 495500.

Gerver, D. (1967). Linguistic rules and the perception and recall of speech by schizophrenic patients. British Journal of Social and Clinical Psychology 6, 204-211.

Gold, G. (1974). The White House Transcripts. Bantam Books: New York.

Grice, H. P. (1975). Logic and conversation. William James Lectures, Harvard University, 1967. In Studies in Syntax (ed. P. Cole and J. Morgan). Academic Press: New York.

Hirsch, S. R. \& Leff, J. P. (1975). Abnormalities in Parents of Schizophrenics. Institute of Psychiatry Monographs. Oxford University Press: London.

Kantorowitz, D. \& Cohen, B. D. (1977). Referent communication in chronic schizophrenia. Journal of Abnormal Psychology 86, 1-9.

Maher, B. (1972). The language of schizophrenia: a review and interpretation. British Journal of Psychiatry 120, 3-17.

Manschrek, T. C., Maher, B. A., Rucklos, M. E. \& White, M. T. (1979). The predictability of thought disordered speech in schizophrenic patients. British Journal of Psychiatry 134, 595-601.

Maratsos, M. P. (1976). The Use of Definite and Indefinite Reference in Young Children. Cambridge University Press: Cambridge.

Pavy, D. (1968). Verbal behaviour in schizophrenia: a review of recent studies. Psychological Bulletin 70, 164-178. 
Rochester, S. R. (1976). Reference as a speech art: an argument for studying the listener. Paper presented at Psychology of Language Conference, University of Stirling, Scotland. In Campbell, R. N. \& Smith, P. T. (eds.) (1978). Recent Advances in the Psychology of Language. Plenum Press: New York.

Rochester, S. R., Harris, J. \& Seeman, M. V. (1973). Sentence processing in schizophrenic listeners. Journal of Abnormal Psychology 3, 350-356.

Rochester, S. R., Martin, J. R. \& Thurston, S. (1977) Thought-process disorder in schizophrenia: the listener's task. Brain and Language 4, 95-114.

Rutter, D. R. (1979). The reconstruction of schizophrenic speech. British Journal of Psychiatry 134, 356-359.

Rutter, D. R., Wishner, J. \& Callaghan, B. A. (1975). The prediction and predictability of speech in schizophrenic patients. British Journal of Psychiatry 126, 571-576.

Rutter, D. R., Draffan, J. \& Davies, J. (1977). Thought disorder and the predictability of schizophrenic speech. British Journal of Psychiatry 131, 67-68.

Rutter, D. R., Wishner, J., Kopytynska, L. \& Button, M. (1978). The predictability of speech in schizophrenic patients. British Journal of Psychiatry 132, 228-232.

Salzinger, K. (1973). Schizophrenia: Behavioural Aspects. John Wiley \& Sons: New York.
Salzinger, K., Portnoy, S. \& Feldman, R. S. (1964). Verbal behaviour of schizophrenic and normal subjects. Annals of the New York Academy of Sciences 105, 845-866.

Schwartz, S. (1978). Language and cognition in schizophrenia: a review. In Language and Cognition in Schizophrenia (ed. S. Schwartz), pp. 237-276. Lawrence Erlbaum: New Jersey.

Siegel, A., Harrow, M., Reilly, F. E. \& Tucker, G. T. (1976). Loose associations and disordered speech patterns in chronic schizophrenia. Journal of Nervous and Mental Disease 162, 105-112.

Silverman, G. (1972). Psycholinguistics of schizophrenic language. Psychological Medicine 2, 254-259.

Singer, M. T. \& Wynne, L. C. (1966). Communication styles in parents of normals, neurotics and schizophrenics. Psychiatric Research Report 20, 25-38.

Truscott, T. P. (1970). Contextual constraint and schizophrenic language. Journal of Consulting and Clinical Psychology 35, 189-194.

White, S. J. (1979). Statistical errors in papers in the British Journal of Psychiatry. British Journal of Psychiatry 135, 336-342.

Wing, J. K., Cooper, J. E. \& Sartorius, N. (1974). Measurement and Classification of Psychiatric Symptoms. Cambridge University Press: Cambridge. 